\title{
CONSTRUÇÃO E ESTUDOS DE PERFOMANCE DE UM REATOR FOTOQUÍMICO TIPO CPC (“COMPOUND PARABOLIC CONCENTRATOR”)
}

Edward Thomas Fleury Mendonça Duarte, Thiago Padovani Xavier, Danilo Rodrigues de Souza, Jacques Antonio de Miranda e Antonio Eduardo da Hora Machado*

Instituto de Química, Universidade Federal de Uberlândia, CP 593, 38408-100 Uberlândia - MG

Christian Jung, Lamark de Oliveira e Christian Sattler

Deutsches Zentrum für Luft- und Raumfahrt e.V.(DLR), Solarforschung, Linder Höhe, D-51147 Köln Porz, Germany

Recebido em 13/1/04; aceito em 27/1/05; publicado na web em 30/6/05

\begin{abstract}
CONSTRUCTION AND PERFORMANCE STUDIES OF A CPC TYPE PHOTOCHEMICAL REACTOR. A CPC (Compound Parabolic Concentrator) reactor was projected and constructed aiming to promote the degradation of the organic matter present in considerable volumes of aqueous effluents, under the action of solar radiation. The essays were done using a model effluent which consists of a mixture of fragments of a sodium salt of lignosulphonic acid possessing a mean molecular weigth of 52,000 Daltons, and a real effluent, from a chip board industry. The volume of effluent in each test was about $50 \mathrm{~L}$. The tests involved heterogeneous ( $\mathrm{TiO}_{2}$ P25 Degussa and formulations made from the association of $\mathrm{TiO}_{2}$ with a photosensitiser), and homogeneous (thermal and photochemical Fenton reactions) catalysis of the effluents. The results demonstrate the viability of application of this kind of reactor even when the load of organic pollutants is high.
\end{abstract}

Keywords: CPC reactor; photocatalysis; waste water.

\section{INTRODUÇÃO}

A industrialização proporcionou à humanidade uma série de benefícios. No entanto, junto com os benefícios, vieram também os efeitos adversos: a produção de resíduos industriais e a conseqüente contaminação do meio-ambiente. O comprometimento dos recursos hídricos é um exemplo do quão preocupante é a ação inconseqüente do homem na biosfera. Os riscos de colapso no fornecimento de água potável já podem ser sentidos em muitas regiões do planeta. Se nada de concreto for feito no sentido de otimizar a reciclagem da água e proteger os mananciais aquíferos, o planeta caminha para o caos.

A grande dificuldade no tratamento de águas residuárias deve-se principalmente à presença de compostos orgânicos não biodegradáveis, resultado das atividades industriais, comerciais e agrícolas ${ }^{1,2}$. Muitos desses contaminantes são espécies bastante estáveis, resistentes à biodegradação e, ao mesmo tempo, extremamente solúveis em água, o que lhes permite, além da contaminação das águas da superfície, penetrar no solo, pondo em risco os lençóis freáticos ${ }^{1}$.

A possibilidade de reciclagem da água, através da inviabilização da carga poluente, empregando Processos Oxidativos Avançados (POA), tem sido evidenciada por muitos pesquisadores ${ }^{1-11}$. Os POA baseiam-se na geração do radical hidroxila $\left({ }^{\circ} \mathrm{OH}\right)$ como agente oxidante $^{1,3,9,10}$. Dentre os POA, encontram-se os processos fotocatalíticos ${ }^{1,9-11}$.

Os processos fotocatalíticos heterogêneos têm sido indicados por sua eficácia na degradação de muitos compostos orgânicos presentes em efluentes aquosos ${ }^{4,5,11}$. Dentre os fotocatalisadores empregados, o dióxido de titânio é o mais atrativo por ser barato, inofensivo ao meio ambiente, fotoestável e de fácil recuperação ${ }^{12}$.

As reações de Fenton são reações catalíticas homogêneas que também envolvem processos fotocatalíticos ${ }^{10,13-15}$. Como os processos heterogêneos, são também capazes de promover a degrada-

*e-mail: aeduardo@ufu.br ção da matéria orgânica presente em águas residuárias ${ }^{8,10,14,15}$. A diferença com relação aos processos heterogêneos está na possibilidade de recuperação do catalisador e na eficiência quântica de geração de radicais hidroxila, que é maior nas reações de Fenton.

No mecanismo aceito para as reações de Fenton nãofotoquímicas, radicais hidroxila são produzidos pela reação entre $\mathrm{Fe}^{2+}$ e peróxido de hidrogênio ${ }^{8,10,14,15-17}$.

$\mathrm{Fe}^{2+}+\mathrm{H}_{2} \mathrm{O}_{2} \rightarrow \mathrm{Fe}^{3+}+\mathrm{HO}^{\circ}+\mathrm{HO}^{-} \rightarrow \mathrm{Fe}(\mathrm{OH})_{2}++\mathrm{HO}^{\circ}$

A formação de $\mathrm{Fe}^{3+}$ e do complexo $\mathrm{Fe}(\mathrm{OH})^{2+}$ resulta em uma série de outras reações combinadas, algumas das quais fotoquímicas, que acabam por regenerar o $\mathrm{Fe}^{2+}$, produzindo elevada concentração estacionária de radicais hidroxila no meio reacional.

Enquanto que usualmente as reações de Fenton fotoquímicas necessitam de fótons com comprimentos de onda próximos de $400 \mathrm{~nm}^{10}$, as reações catalisadas por dióxido de titânio necessitam de fótons mais energéticos, de comprimentos de onda inferiores a $390 \mathrm{~nm}^{9,18}$.

A utilização econômica de processos baseados no aproveitamento da radiação solar no tratamento de águas residuárias vem sendo proposta tendo em vista seu baixo custo, principalmente em países com elevado grau de insolação ${ }^{2-15,19,20}$. A tecnologia já se encontra disponível ${ }^{2,5,7,8,19,21,22}$. Infelizmente, embora plantas-piloto de tratamento em larga escala tenham comprovado sua viabilida$\mathrm{de}^{2,19,21,22}$, a aplicação prática tem sido vista com excessiva cautela pelos reais interessados. Por essa razão, projetos com o envolvimento de potenciais usuários são importantes no sentido de reduzir as barreiras à sua implementação.

Os reatores que têm sido empregados na descontaminação fotocatalítica de águas residuárias usando radiação solar podem ser classificados em três grupos, quanto à forma como o efluente a ser tratado circula através do reator (vaso agitado, filme corrente ou tubular), e em dois grupos, quanto ao modo como o catalisador é aplicado (em suspensão ou imobilizado) ${ }^{19,23,24}$. 
Os reatores CPC ("Compound Parabolic Concentrators") e PTC (Parabolic-Trough Concentrators) são exemplos de reatores tubulares. Os PTC, mais antigos, têm os refletores com formato de calha parabólica. Tubos de vidro borossilicato, através dos quais o efluente a ser tratado circula, são montados nos focos dessas calhas. A principal desvantagem desses reatores é o fato de não aproveitar a radiação solar difusa, mas apenas a radiação direta ${ }^{19}$. Por outro lado, a eficiência ótica típica para esse tipo de reator é por volta de $50 \%{ }^{19}$.

Nos reatores CPC, as superfícies refletoras são moldadas no formato de involuta, posicionadas ao redor dos tubos cilíndricos de vidro borossilicato (Figuras 1 e 2) por onde circula o efluente a ser tratado $^{2,19}$. Embora não concentrem a radiação solar incidente, esses reatores sobressaem-se pelo seu baixo custo, por não necessitarem de partes móveis, serem de fácil instalação e manutenção, e apresentarem bom aproveitamento da radiação solar incidente, inclusive das componentes difusas $2,7,8,19,22,23$.
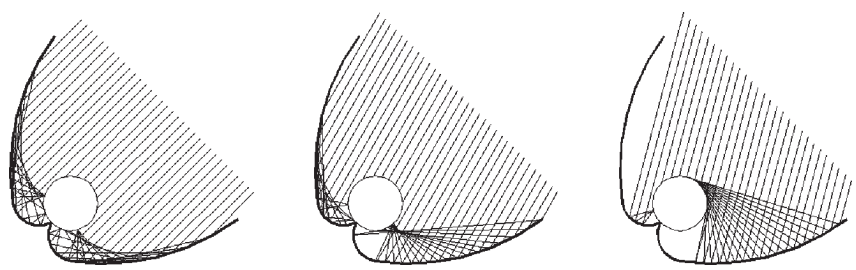

Figura 1. Representação em perfil mostrando o formato de involuta dos refletores de um reator $C P C$ e as diversas formas de captação da radiação incidente

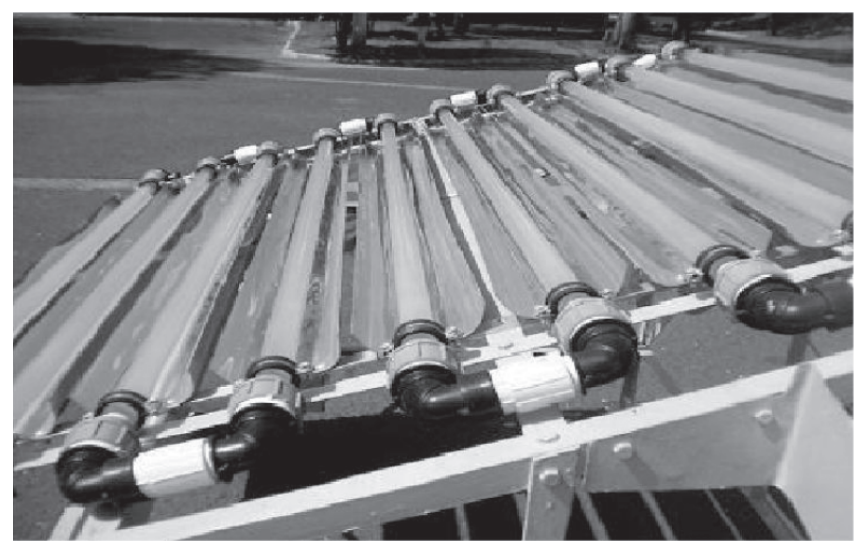

Figura 2. Detalhe da superficie refletora de um reator $C P C$

O fluxo nos reatores tubulares é usualmente turbulento, o que pode causar perdas de eficiência na captação da radiação solar. No entanto, essa dificuldade pode ser minimizada durante o projeto, e com o emprego de quantidades balanceadas do catalisador, no caso da fotocatálise heterogênea, de forma que se garanta uma distribuição uniforme no efluente a ser tratado, minimizando possíveis efeitos de coabsorção da radiação incidente ${ }^{25}$.

No presente artigo, são apresentados detalhes relativos ao projeto e construção de um protótipo de reator CPC com área total irradiada de $1,62 \mathrm{~m}^{2}$, assim como resultados de ensaios fotocatalíticos que vêm sendo realizados com objetivo de avaliar a performance e aplicabilidade desse tipo de reator nas condições vigentes no país.

\section{PARTE EXPERIMENTAL}

A estrutura do reator foi construída empregando ferro chato e na forma de cantoneira, ambos com $3,18 \mathrm{~cm}$ de largura e $0,25 \mathrm{~cm}$ de expessura. A base para a superfície refletora foi montada com uma inclinação de $19^{\circ}$ referente à latitude da cidade de Uberlândia garantindo, assim, um melhor aproveitamento da radiação incidente. A superfície refletora foi construída empregando-se chapas de alumínio anodizado de 0,8 $\mathrm{mm}$ de espessura, $1,25 \mathrm{~m}$ de comprimento, e 0,11 m de largura, curvadas no formato de involutas (Figuras 1 e 2). As involutas foram fixadas sobre a estrutura metálica, empregando rebites. Sobre essas, foram suportados os tubos de vidro borossilicato. Esses, de $32 \mathrm{~mm}$ de diâmetro externo, 29,2 mm de diâmetro interno, e $1,50 \mathrm{~m}$ de comprimento, foram conectados em série.

A Figura 3 apresenta esquematicamente um reator CPC.

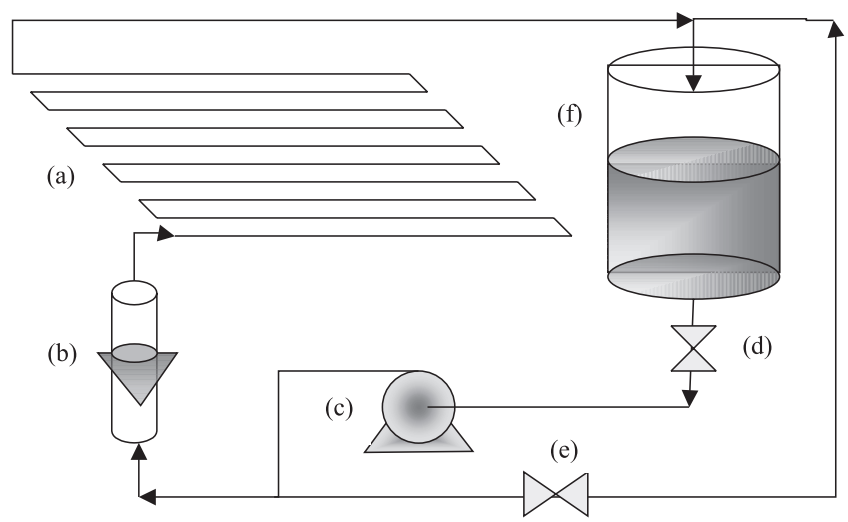

Figura 3. Representação esquemática de um reator CPC: (a) tubos de vidro dispostos em série; (b) medidor de vazão; (c) bomba centrífuga; (d) sistema "by-pass"; (e) registro de gaveta e (f) reservatório

A área da superfície coletora é igual a $1,62 \mathrm{~m}^{2}$ e o volume efetivo de reação, de $12 \mathrm{~L}$. O reator é dotado de um reservatório para o efluente a ser tratado, com capacidade máxima de 120 L. O volume total de operação é de 140 L. Uma bomba centrífuga de $0,50 \mathrm{CV}$, com rotor e carcaça confeccionados em material inerte, viabiliza a circulação do efluente, com vazão máxima de $2 \mathrm{~m}^{3} / \mathrm{h}$.

A Figura 4 apresenta o reator em operação.

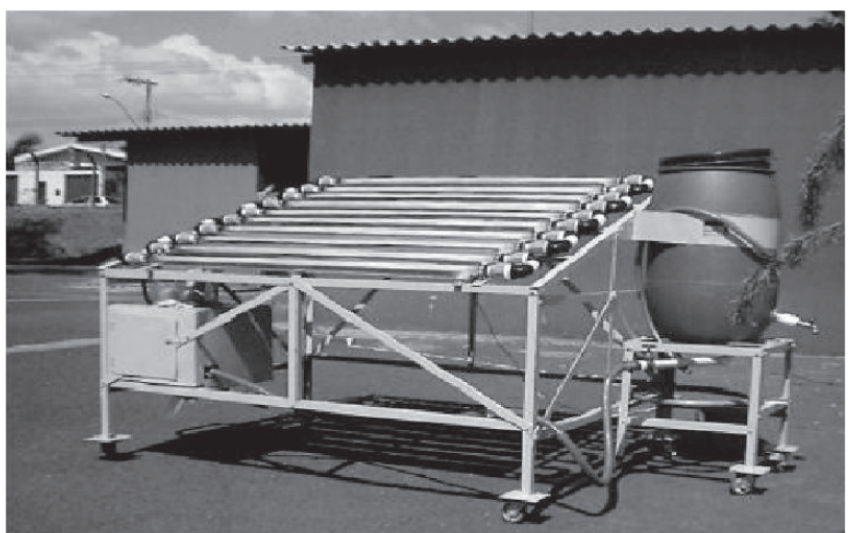

Figura 4. Reator CPC em operação nas dependências do IQ-UFU

\section{Cálculo da potência da bomba centrífuga ${ }^{26,27}$}

Conhecidas as especificações das tubulações, supôs-se, para os efluentes a serem tratados, uma viscosidade cinemática igual à da água, o que é coerente, já que usualmente a concentração de contaminantes não é suficiente para alterar essa propriedade. Para os cálculos, a temperatura de operação do reator foi estabelecida como $313 \mathrm{~K}$, tomando-se por base resultados prévios, obtidos pelo 
emprego de um protótipo tipo reator PTC. A $313 \mathrm{~K}$, a viscosidade cinemática da água é igual a $0,695 \times 10^{-6} \mathrm{~m}^{2} \mathrm{~s}^{-1}$.

Algumas características das tubulações, necessárias para os cálculos, são apresentados na Tabela 1.

Tabela 1. Características das tubulações empregadas na confecção do reator tipo CPC

\begin{tabular}{lcc}
\hline & $\begin{array}{c}\text { Tubos de vidro } \\
\text { borossilicato }\end{array}$ & $\begin{array}{c}\text { Tubos } \\
\text { de PVC }\end{array}$ \\
\hline Diâmetro nominal $(\mathrm{mm})$ & 32 & 32 \\
Diâmetro interno $(\mathrm{mm})$ & 29,2 & 25,4 \\
Comprimento $(\mathrm{m})$ & 10 & 7 \\
E/D* & $5 \times 10^{-5}$ & $1 \times 10^{-4}$ \\
\hline
\end{tabular}

*E/D é a razão entre a rugosidade do tubo (m) e o diâmetro do tubo (m)

Todas as tubulações plásticas foram consideradas, para simplificação dos cálculos, como possuindo características de tubulações de PVC.

O cálculo da energia necessária para promover a eficiente circulação do fluido, considerando-se todo o percurso e seus acidentes, baseou-se na Equação de Bernoulli,

$\frac{\mathrm{P}_{1}}{\gamma}+\frac{\mathrm{v}_{1}^{2}}{2 \mathrm{~g}}+\mathrm{z}_{1}=\frac{\mathrm{P}_{2}}{\gamma}+\frac{\mathrm{v}_{2}^{2}}{2 \mathrm{~g}}+\mathrm{z}_{2}+\mathrm{h}_{\mathrm{T}}$

onde P é a pressão exercida sobre o fluido; $\gamma$, o peso específico do fluido; g, a constante gravitacional; v, a velocidade do fluido; $\mathrm{z}$, a cota de altura do fluido e $\mathrm{h}_{\mathrm{T}}$, a perda de carga devida a acidentes e irregularidades da tubulação. Esta, é expressa como

$h_{T}=F \cdot \frac{v^{2}}{2 g} \cdot\left(\frac{L}{D}+\sum_{i} \frac{L_{e}}{D}\right)+\sum_{i} k \cdot \frac{v^{2}}{2 g}$

onde L é o comprimento real do tubo; $\mathrm{L}_{\mathrm{e}}$, o comprimento considerando-se todos os acidentes ${ }^{26} ; \mathrm{k}$, uma constante que depende do tipo de acidente ${ }^{26,27}$ e F, o fator de atrito.

O fator de atrito é um número adimensional e é função do número de Reynolds (Re) e da razão entre a rugosidade $(\varepsilon)$ e o diâmetro (D) do tubo,

$F=\left[2 \log \left(\frac{0,27 \varepsilon}{D}+\left(\frac{7}{R_{e}^{0,9}}\right)\right)\right]^{-2}$

A Tabela 2 apresenta valores para $\mathrm{L}_{\mathrm{e}} / \mathrm{D}$ e $\mathrm{k}$ para os acidentes observados no percurso a ser percorrido pelo fluido.

Tabela 2. Valores tabelados para os acidentes que ocorrem nas tubulações ${ }^{25,26}$

\begin{tabular}{lccc}
\hline Tipo de Acidente & Quantidade & $\mathrm{L}_{\mathrm{e}} / \mathrm{D}(\mathrm{m})$ & $\mathrm{k}$ \\
\hline Joelhos $90^{\circ}$ & 20 & 41 & - \\
Registro de esfera & 02 & 40 & - \\
União & 20 & - & 0,04 \\
Saída e Entrada & 02 & - & 1,5 \\
Medidor de vazão & 01 & - & 2,5 \\
Bifurcação em “T” & 01 & 60 & - \\
\hline & Total & 940 & 6,3 \\
\hline
\end{tabular}

O desnível de altura (altura para a qual a bomba deve transportar o fluido), $\Delta \mathrm{z}$, foi superestimado como sendo $2 \mathrm{~m}$, de modo que no resultado final se garanta uma potência excedente, necessária para manter uma eficiente circulação do efluente.

A velocidade do fluido nas tubulações foi arbitrada de modo a que o regime de transporte fosse turbulento, garantindo uma melhor homogenização do material a ser tratado. Por simplificação, a velocidade do fluido foi expressa em termos da vazão volumétrica, $\dot{\mathrm{V}}$. $\mathrm{Na}$ arbitragem desse parâmetro, tomou-se como referência o fato de que a vazão volumétrica recomendada nos manuais de bombas centrífugas para tubulações de $32 \mathrm{~mm}$ de diâmetro interno, está entre 1 e $2 \mathrm{~m}^{3} / \mathrm{h}$. Assim, o valor arbitrado foi o máximo $\left(2 \mathrm{~m}^{3} / \mathrm{h}\right)$, próximo do estimado para tubulações plásticas. A partir daí, foi possível calcular o número de Reynolds para o escoamento do fluido através do vidro e das tubulações plásticas

$\operatorname{Re}=\frac{D \cdot v \cdot \rho}{\mu}=\frac{4 \dot{V}}{\pi \cdot v \cdot D}$

onde, $\mu$ é a viscosidade do fluido, $\rho$, sua densidade, e a razão $\mu / \rho$ é a viscosidade cinemática.

Da Equação 4 tem-se, então, que $\operatorname{Re}_{\text {vidro }}=34.855,4(\mathrm{v}=0,8 \mathrm{~m} / \mathrm{s})$, $\mathrm{e} \mathrm{Re}_{\mathrm{PVC}}=40.070,0(\mathrm{v}=1,1 \mathrm{~m} / \mathrm{s})$.

Os Fatores de Atrito foram, então, calculados para ambos os materiais, considerando-se suas diferentes rugosidades relativas, estimadas a partir do diagrama de Moody ${ }^{26}$, considerando-se que ambos (vidro e PVC) se inserem na classe dos tubos hidraulicamente $\operatorname{lisos}^{26}$. Os Fatores de Atrito correspondentes são $\mathrm{F}_{\text {vidro }}=$ 0,0239 e $\mathrm{F}_{\mathrm{PVC}}=0,0233$.

Com base nos Fatores de Atrito e nos dados dispostos na Tabela 2, pode-se estimar o valor de perda de carga como sendo igual à soma das perdas de carga no vidro e no PVC, resultando em um valor igual a 3,57 $\mathrm{m}$ de coluna de água.

Pela aplicação da Equação de Bernoulli (Equação 1), estimouse, então, a diferença de pressão exercida pela bomba

$\mathrm{P}_{2}-\mathrm{P}_{1}=\Delta \mathrm{P}=\mathrm{Y} \cdot\left(\frac{\mathrm{v}^{2}}{2 \mathrm{~g}}+\mathrm{h}_{\mathrm{T}}+\Delta \mathrm{z}\right)=55.191 \mathrm{~Pa} \quad$ para $\Delta \mathrm{Z}=2 \mathrm{~m}$

A eficiência mecânica para a bomba, $\eta$, foi arbitrada como sendo em torno de 0,5, abaixo do esperado para esse tipo de bomba, conforme manuais de bombas centrífugas. Isso foi considerado de maneira a garantir uma potência excedente para a bomba centrífuga

$\mathrm{W}=\frac{\Delta \mathrm{P} \cdot \dot{\mathrm{V}}}{\eta} \approx 0,14 \mathrm{CV}$

Visando uma expansão futura do reator, optou-se pela aquisição de uma bomba centrífuga de maior capacidade $(0,50 \mathrm{CV})$. Optou-se, visando uma maior vida útil, por uma bomba com rotor e carcaça construídos em material polimérico inerte.

\section{Ensaios fotocatalíticos}

Nos estudos de performance do reator CPC, para ensaios de degradação empregando como catalisadores, dióxido de titânio, P25 (Degussa AG), e compósitos ${ }^{28}$, um sal sódico do ácido lignossulfônico (Aldrich, cód. 47103-8) foi usado para mimetizar a carga orgânica do efluente produzido por indústrias de papel e celulose ${ }^{4}$. A massa de catalisador empregada nos ensaios foi de $100 \mathrm{mg}$ por litro de efluente.

Os compósitos empregados consistem de uma combinação de dióxido de titânio e um corante fotossensibilizador (ftalocianina de zinco ${ }^{28,29}$. Estes, foram idealizados visando maximizar a captação de radiação durante o tratamento de efluentes aquosos em processos fotocatalíticos heterogêneos empregando radiação $\operatorname{solar}^{28}$. 
Nos ensaios empregando as reações de Fenton, foram utilizadas amostras reais de efluente fornecidas pela empresa SATIPEL. Uma massa de $50 \mathrm{mg} / \mathrm{L}$ de sulfato ferroso heptaidratado P.A., VETEC, foi empregada como catalisador, para um volume de $50 \mathrm{~L}$ de efluente.

Peróxido de hidrogênio 30\%, VETEC, foi empregado em ambos os processos como fonte de radicais hidroxila ${ }^{4,8}$. Os ajustes de pH necessários foram feitos empregando soluções aquosas de ácido sulfúrico e de hidróxido de sódio. $\mathrm{O} \mathrm{pH}$ do efluente antes de receber o tratamento fotocatalítico foi ajustado para 2,90 $\pm 0,10$ em ambos os casos ${ }^{4,8}$.

A Demanda Química de Oxigênio (DQO) medida para as soluções não tratadas de lignossulfonato foi em torno de $400 \mathrm{mg} / \mathrm{L}$, enquanto que para o efluente a ser tratado com as reações de Fenton, variou entre 1000 e $4000 \mathrm{mg} / \mathrm{L}$. As análises de DQO foram feitas por via espectrofotométrica utilizando um Espectrofotômetro HACH DR-4000U, um digestor de mesma procedência, além de cubetas de teste contendo os reagentes, manipulados conforme recomendações do fabricante $(\mathrm{HACH})$.

Alíquotas de $2 \mathrm{~mL}$ do efluente foram coletadas durante a reação, a intervalos de tempo de $30 \mathrm{~min}$, sendo acrescentadas nas cubetas contendo a solução de teste, as quais eram digeridas a 393 $\mathrm{K}$, durante $2 \mathrm{~h}$. Após esse tempo e equalização da temperatura, as medidas de DQO eram feitas.

As medidas da dose de radiação UV-A incidente foram feitas empregando um Radiômetro Solar Ligth, PMA-2100, versão 1.16, equipado com detetor UV-A.

Medidas de reflectância difusa foram feitas para os compósitos e para o $\mathrm{TiO}_{2}$ puro, empregando um espectrofotômetro Perkin-Elmer Lambda 19, equipado com esfera integradora. A fim de atenuar o sinal de reflectância difusa, as amostras foram preparadas por diluição a $1 \%$ em sulfato de bário. Os espectros foram obtidos utilizando-se sulfato de bário como referência, considerando-se sua elevada reflectância no intervalo onde foram efetuadas as medidas.

\section{RESULTADOS E DISCUSSÃO}

\section{Estudos de performance}

Fotocatálise heterogênea: degradação de um modelo de efluente contendo fragmentos de lignossulfonato

Em trabalhos recentes, foi apresentado um estudo da degradação de efluente típico de uma indústria de papel e celulose $e^{4,7}$. Por razões práticas, desenvolveu-se um modelo para esse tipo de efluente, baseado em um derivado parcialmente degradado de um sal sódico do ácido lignossulfônico ${ }^{4}$. Nos ensaios apresentados no presente trabalho, que visam mais a comparação da performance dos catalisadores selecionados, empregou-se esse sal sem qualquer pré-tratamento. Esse composto, segundo o fornecedor, possui uma massa molecular média de 52.000 Daltons.

Em linhas gerais, as reações mediadas pelo $\mathrm{TiO}_{2}$ baseiam-se na formação de pares elétron-lacuna após sua excitação eletrônica e a eficácia do processo fotocatalítico dependerá do tempo em que esses pares subsistem sem que ocorra recombinação ${ }^{18}$.

A Figura 5 apresenta o perfil de degradação obtido para soluções contendo lignossulfonato, expresso em termos de DQO normalizada.

É evidente que a cinética das reações envolvendo os compósitos deve ser bem diferente das mediadas pelo $\mathrm{TiO}_{2}$. Nesses compósitos, o corante fotossensibilizador ao ser eletronicamente excitado, tende a injetar elétrons na banda de condução do $\mathrm{TiO}_{2}$, o que proporciona o ganho de eficiência observado ${ }^{28,29}$. Também, é possível que haja, nesse caso, a participação do oxigênio singlete como espécie

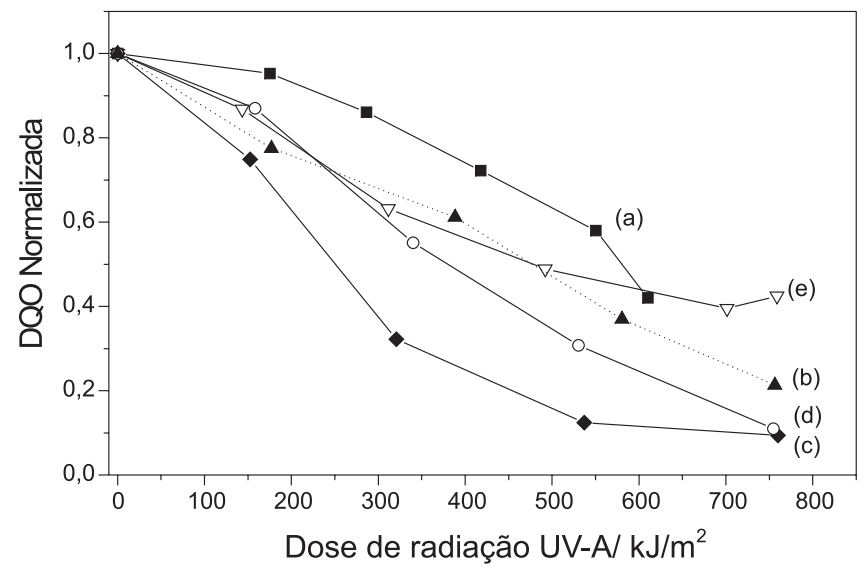

Figura 5. Relação DQO normalizada vs. dose de radiação $U V$-A, obtida durante a degradação da matéria orgânica presente em $50 \mathrm{~L}$ de efluente, por fotocatálise heterogênea ( $1 \mathrm{~mL}$ de $\mathrm{H}_{2} \mathrm{O}_{2}$ adicionado por L de efluente): (a) P25; (b) compósito com 1,0\% de ftalocianina de zinco (FtZn); (c) compósito com 2,5\% de FtZn; (d) compósito com 5,0\% de FtZn e (e) compósito com $10,0 \%$ de FtZn

reativa, já que a ftalocianina de zinco, além de intermediar reações Tipo I (transferência de elétron), é também eficiente na sensitização de reações Tipo II (transferência de energia) ${ }^{30,31}$.

Uma redução na DQO de cerca de $60 \%$ foi obtida empregandose $\mathrm{TiO}_{2}$ como catalisador, após uma dose acumulada de radiação UV-A de cerca de $610 \mathrm{~kJ} / \mathrm{m}^{2}$, o que corresponde, nas condições da cidade de Uberlândia, em um dia ensolarado, a menos de $2 \mathrm{~h}$ de reação, ou 4 h para um dia de nebulosidade moderada a alta. Observa-se um substancial aumento na velocidade de degradação ao se empregar os compósitos ${ }^{23}$ : no caso do compósito contendo $2,5 \%$ em massa de ftalocianina de zinco, por ex., o mesmo resultado pode ser alcançado com cerca de $290 \mathrm{~kJ} / \mathrm{m}^{2}$, enquanto que com cerca de $610 \mathrm{~kJ} / \mathrm{m}^{2}$, uma redução na DQO em torno de $90 \%$ pode ser atingida. Com o compósito a 10,0\%, o que forneceu o pior resultado do conjunto, o nível de degradação alcançado é similar ao obtido com o $\mathrm{TiO}_{2}$ puro. $\mathrm{O}$ que pode estar ocorrendo neste caso é uma saturação no recobrimento da superfície pelo fotossensibilizador, acarretando em maior agregação dessas moléculas, prejudicando a formação dos pares elétron-lacuna a partir da excitação direta do catalisador ${ }^{18,29}$.

A Figura 6 apresenta espectros de reflectância difusa para o $\mathrm{TiO}_{2}$ e alguns dos compósitos estudados.

Pode-se observar nos espectros dos compósitos, que a banda Q da ftalocianina de zinco perdeu a estrutura, sugerindo a ocorrência de agregação ${ }^{30}$. Essa banda apresenta um máximo de absorção a $684 \mathrm{~nm}$, deslocado do seu valor típico, muito provavelmente em função de interações entre a ftalocianina de zinco e a superfície do catalisador. A banda Soret da ftalocianina de zinco apresenta-se sobreposta pela banda característica do $\mathrm{TiO}_{2}$, bastante intensa na região do ultravioleta. As bandas Soret (também conhecida por banda benzenóide, B) e Q são bandas de absorção comuns em compostos macrocíclicos contendo um sistema $\pi$ conjugado. Esses termos são designações espectroscópicas para transições eletrônicas envolvendo orbitais moleculares $\pi$ e $\pi^{*}$. A banda Q é uma típica banda conjugada (ou de conjunto) e sua característica é uma intensa absortividade molar no visível ${ }^{32-35}$.

Deve-se observar que a capacidade de aproveitamento de fótons para o processo catalítico por esses compósitos não se restringe a comprimentos de onda menores que $390 \mathrm{~nm}$, como ocorre com o $\mathrm{TiO}_{2}$. Com a incorporação do fotossensibilizador, ocorre também um aproveitamento de fótons de comprimentos de onda superiores 


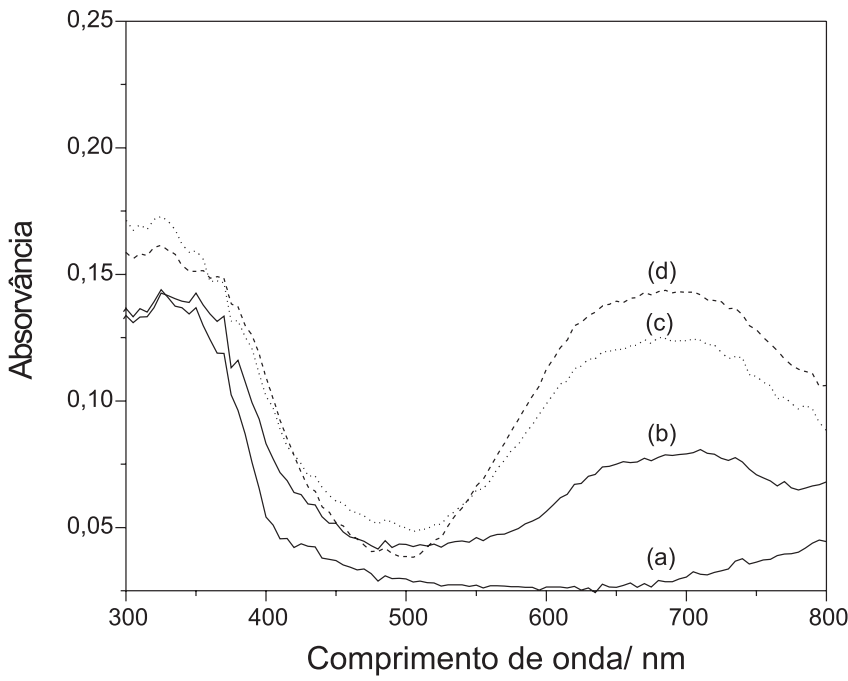

Figura 6. Espectros de reflectância difusa dos catalisadores formulados em diferentes razões $\mathrm{m} / \mathrm{m}$, diluídos a $1 \%$ em sulfato de bário: (a) P25; (b) compósito com 1,0\% de FtZn; (c) compósito com 2,5\% de FtZn; (d) compósito com 5,0\% de FtZn. Sulfato de bário foi usado como referência

a $500 \mathrm{~nm}$, muito provávelmente em processos de transferência de energia (reações tipo II), aliado à adicional injeção de elétrons à banda de condução do $\mathrm{TiO}_{2}$, em virtude da sobreposição da banda Soret da ftalocianina de zinco com a banda de absorção do óxido de titânio ${ }^{29}$.

\section{Fotocatálise homogênea empregando reações de Fenton}

As Figuras 7 e 9 apresentam a degradação da matéria orgânica presente no efluente da SATIPEL S.A., obtida empregando as reações de Fenton.

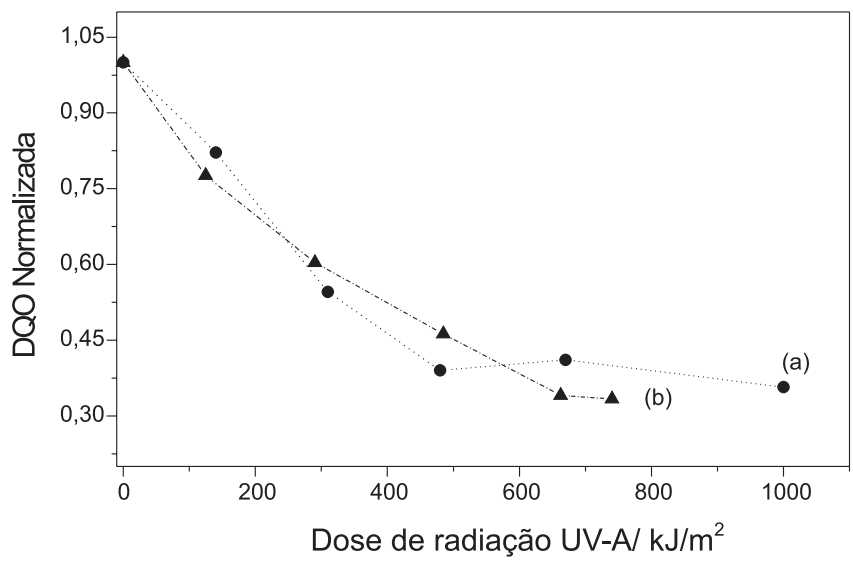

Figura 7. Relação DQO normalizada vs. dose de radiação $U V-A$, obtida durante a degradação da matéria orgânica presente em $50 \mathrm{~L}$ de efluente, por fotocatálise homogênea, empregando as reações de Fenton, segundo a adição de $\mathrm{H}_{2} \mathrm{O}_{2}$ (Volume total adicionado: $6 \mathrm{~mL}$ por $\mathrm{L}$ de efluente): (a) $50 \%$ do volume foi adicionado no início da reação, 33\% a 120 min e $17 \%$ a $240 \mathrm{~min}$; (b) 50\% do volume foi adicionado no início da reação e os outros $50 \%$ após $150 \mathrm{~min}$

Pode-se observar que na situação na qual a adição de $\mathrm{H}_{2} \mathrm{O}_{2}$ é mais distribuída, a degradação tende a ser superior. No entanto, o peróxido de hidrogênio não consumido tende a majorar o resultado. A Figura 8 apresenta uma relação entre a DQO e a quantidade de peróxido de hidrogênio adicionado, que permite estimar o nível de majoração esperado no valor da DQO em função da concentração de $\mathrm{H}_{2} \mathrm{O}_{2}$ no meio.

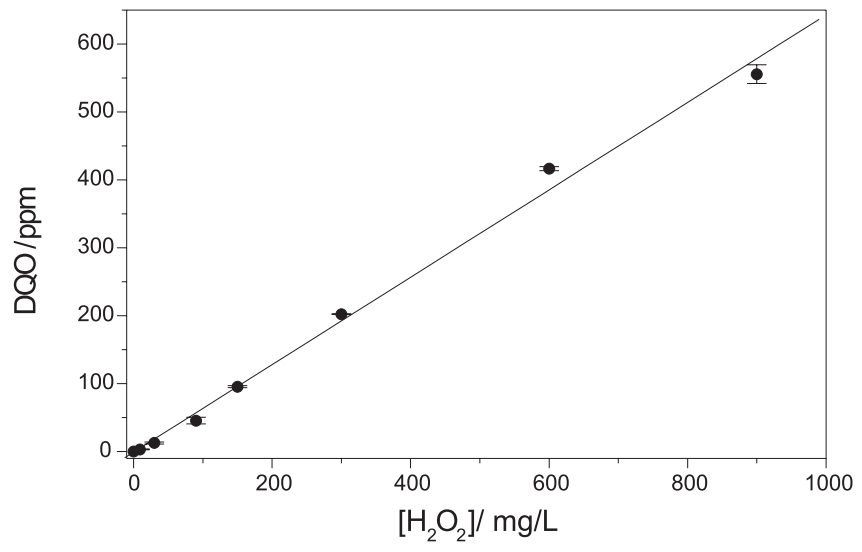

Figura 8. Relação entre DQO e concentração de peróxido de hidrogênio em solução

Na Figura 9 é apresentado o resultado da degradação de uma amostra de efluente da SATIPEL cuja DQO inicial era de 1000 ppm. Neste caso, monitorou-se também o consumo do peróxido de hidrogênio. Este foi todo adicionado no início da reação (no caso, $3 \mathrm{~mL}$ de $\mathrm{H}_{2} \mathrm{O}_{2}$ por litro de efluente).

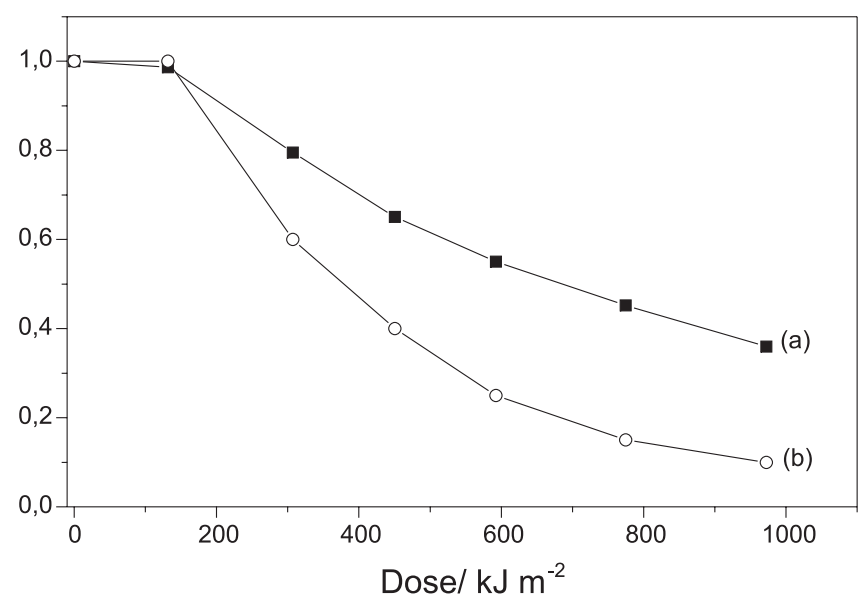

Figura 9. Degradação da matéria orgânica presente em $50 \mathrm{~L}$ de efluente, por fotocatálise homogênea, empregando as reações de Fenton: (a) DQO normalizada e (b) quantidade relativa de peróxido de hidrogênio

A redução de DQO estimada após uma dose de $1000 \mathrm{~kJ} / \mathrm{m}^{2}$ foi de cerca de $66 \%$. Neste ponto, havia ainda cerca de $10 \%$ do peróxido de hidrogênio adicionado. Com base na curva da Figura 8, há uma componente na DQO igual a 57 ppm decorrente do $\mathrm{H}_{2} \mathrm{O}_{2}$ que não reagiu. Assim, a redução real de DQO estimada para esse efluente foi em torno de $72 \%$.

Em linhas gerais, os níveis atingidos de redução da DQO são bastante significativos, principalmente considerando-se os elevados valores medidos para o efluente inicial. Na fase atual dos testes, tem sido possível atingir uma redução próxima de $100 \%$ na DQO dos efluentes ${ }^{8}$.

Tem-se observado que a reação de Fenton térmica é beneficiada nesse processo, quando a temperatura do meio reacional excede $313 \mathrm{~K}^{8}$.

A regeneração do $\mathrm{Fe}^{2+}$, e conseqüente revitalização da reação de Fenton térmica, ocorre por foto-redução do $\mathrm{Fe}^{3+}$ e do complexo $\mathrm{Fe}(\mathrm{OH})^{2+}$, o que implica em mais radicais hidroxila no meio reacional ${ }^{10}$. Esse processo ocorre com maior eficiência em $\mathrm{pH}$ inferior a 3, mais específicamente em torno de $2,8^{8,10}$. 
Os processos apresentados neste trabalho foram levados a cabo no mesmo reator CPC. Deve-se ressaltar no entanto que, embora uma comparação da performance dos dois processos não tenha sido abordada no presente trabalho, ensaios empregando $\mathrm{TiO}_{2}$ ou os compósitos na degradação da matéria orgânica presente no efluente da SATIPEL S. A. não foram bem-sucedidos, resultando em reduções de DQO inferiores a 30\% para doses de até $1000 \mathrm{~kJ} / \mathrm{m}^{2}$. Estudos no sentido de elucidar as causas desse comportamento encontram-se em andamento.

\section{CONCLUSÃO}

O reator CPC apresenta elevada performance para tratamento de efluentes aquosos empregando tanto fotocatálise homogênea como heterogênea, com aproveitamento de radiação solar.

No tratamento fotocatalítico empregando as reações de Fenton, uma expressiva redução na DQO foi atingida para efluentes possuindo elevada carga orgânica, para os quais o tratamento por fotocatálise heterogênea não foi bem-sucedido. Na degradação da matéria orgânica presente no modelo de efluente contendo um sal de ácido lignossulfônico, via fotocatálise heterogênea, os compósitos apresentados conferiram maior eficiência ao processo, sobretudo o contendo $2,5 \%$ em massa de fotossensibilizador, onde uma redução da DQO do efluente em torno de $90 \%$ foi atingida com uma dose de radiação UV-A de cerca de $610 \mathrm{~kJ} / \mathrm{m}^{2}$.

\section{AGRADECIMENTOS}

Convênio CNPq/DLR (COIN 910056/00-5), BMBF (Bundesministerium für Bildung und Forschung), $\mathrm{CNPq} \mathrm{e}$ FAPEMIG, pelo apoio financeiro, e SATIPEL S.A. pela cessão do efluente.

\section{REFERÊNCIAS}

1. Ziolli, R. L.; Jardim, W. F.; Quim. Nova 1998, 21, 319

2. Milow, B.; Blanco, J.; Fernández, P.; Malato, S.; Richter, C.; Funken, K. H.; Sattler, C.; REWAS 99 Proceedings, San Sebastian, Spain, 1999.

3. Legrini, D.; Oliveros, E.; Braun, A. M.; Chem. Rev. 1993, 93, 671.

4. Machado, A. E. H.; Miranda, J. A.; Freitas, R. F.; Duarte, E. T. F. M.; Ferreira, L. F.; Albuquerque, Y. D. T.; Ruggiero, R.; Sattler, C.; Oliveira, L.; J. Photochem. Photobiol., A 2003, 155, 231.

5. Bauer, R.; Waldner, G.; Fallmann, H.; Hager, S.; Klare, M.; Krutszler, T.; Malato, S.; Maletzky, P.; Catal. Today 1999, 53, 131.

6. Huston, P. L.; Pignatello, J. J.; Water Res. 1999, 33, 1238.
7. Sattler, C.; de Oliveira, L.; Tzschirner, M.; Machado, A. E. H.; Energy 2004, 29, 835 .

8. Machado, A. E. H.; Xavier, T. P.; Souza, D. R.; De Miranda, J. A.; Mendonça Duarte, E. T. F.; Ruggiero, R.; De Oliveira, L.; Sattler, C.; Solar Energy 2004, 77, 583

9. Fujishima, A; Rao, T. N.; Tryk, D. A.; J. Photochem. Photobiol., C 2000, 1,1 .

10. Pignatello, J. J.; Environ. Sci. Technol. 1992, 26, 944.

11. Serpone, N. J.; J. Photochem. Photobiol., A 1997, 104, 1.

12. Litter, M. I.; Navío, J. A.; J. Photochem. Photobiol., A 1996, 98, 171

13. Oliveros, E.; Legrini, O.; Hohl, M.; Muller, T.; Braun, A. M.; Water Sci. Technol. 1997, 35, 223.

14. Pignatello, J. J.; Liu, D.; Huston, P.; Environ. Sci. Technol. 1999, 33, 1832

15. Bossmann, S. H.; Oliveros, E.; Göb, S.; Siegwart, S.; Dahlen, E. P.; Payawan, L.; Straub, M.; Wörner, M.; Braun, A. M.; J. Phys. Chem. 1998, $102,5542$.

16. Liu, X. L.; Xu, D.; Wu, F.; Liao, Z. H.; Liu, J. T.; Deng, N. S.; Photochem. Photobiol. 2004, 79, 259.

17. Hardwick, T. J.; Can. J. Chem. 1957, 35, 428.

18. Hoffmann, M.; Martin, S.; Choi, W.; Bahnemann, D. W.; Chem. Rev. 1995, 95, 69.

19. Malato, S.; Blanco, J.; Vidal, A.; Richter, C.; Appl. Catal., B 2002, 37, 1.

20. Feng, W.; Nansheng, D.; Chemosphere 2000, 41, 1137.

21. Sattler, C.; Funken, K. -H.; de Oliveira, L.; Tzschirner, M.; Machado, A. E. H.; Water Sci. Technol. 2004, 49, 189.

22. Malato, S.; Blanco, J.; Vidal, A.; Fernández, P.; Cáceres, J.; Trincado, P.; Oliveira, J. C.; Vincent, M.; Chemosphere 2002, 47, 235.

23. Giménez, J.; Curcó, D.; Queral, M. A.; Catal. Today 1999, 54, 229.

24. Guillard, C.; Disdier, J.; Monnet, C.; Dussaud, J.; Malato, S.; Blanco, J.; Maldonado, M. I.; Herrman, J. M.; Appl. Catal., B 2003, 46, 319.

25. Fernández-Ibañez, P.; Malato, S.; de Las Nieves, F. J.; Catal. Today 1999, 54,195 .

26. Welty, J. R.; Wicks, C. E.; Wilson, R. E.; Fundamentals of Momentum, Heat and Mass Transfer, $3^{\text {rd }}$ ed., John Wiley \& Sons: New York, 1984.

27. Simpson, L. L.; Weirick, M. L.; Chem. Eng. Mag. 1980, 3.

28. Machado, A. E. H.; de Miranda, J. A.; Sattler, C.; De Oliveira, L.; Patente, Depósito no INPI PI 0300950-3, 2003; PCT/BR 2004/000052, 2004; PCT/ WO 2004/089525 A2, 2004

29. Machado, A. E. H.; Velani, V.; Guilardi, S.; de Faria Franca, E.; de Miranda, J. A.; Sattler, C.; de Oliveira, L.; Schmücker, M.; Composite Sci. Technol., submetido.

30. Ribeiro, J.; Dissertação de Mestrado, Universidade Federal de Uberlândia, Brasil, 2003.

31. Owens, J. W.; Smith, R.; Robinson, R.; Robins, M.; Inorg. Chim. Acta 1998, $279,226$.

32. Silverstein, R. M.; Clayton Bassler, G.; Morrill, T. C.; Spectrometric Identification of Organic Compounds, $5^{\text {th }}$ ed., John Wiley \& Sons: New York, 1991.

33. Sun, Li.; Wang, S.; Dyes Pigm. 2004, 61, 273.

34. Franzen, S.; Moore, L. J.; Woodruff, W. H.; Boxer, S. G.; J. Phys. Chem. B 1999, 103, 3070 .

35. George, R. G.; Padmanabhan, M.; Proc.- Indian Acad. Sci., Chem. Sci. 2003, 115, 263. 